\title{
A Call to World Governments: Save Youth Generations from Obsoleted Education Systems!
}

\author{
Dalia Mabrouk \\ Assistant Professor, Suez Canal University, Egypt \\ E-mail: dmabrouk2009@hotmail.com
}

Received: October 11, 2021 Accepted: November 28, 2021 Published: December 5, 2021

doi:10.5296/gjes.v7i2.19309 URL: https://doi.org/10.5296/gjes.v7i2.19309

\begin{abstract}
My research is a result of accumulated provocation of obsolete and paralyzing education that has been frozen since the middle ages. We have to admit that before the pandemic, education was already in crisis. Governments have been ignoring to adopt any comprehensive plan to reform the educational systems till it has been unprecedently disrupted by COVID-19. I try through this paper to make a global call for governments to immediately start cooperating together for setting international qualifications framework that best suit future competencies. This call should be prioritized on the world agenda. It would be more plausible for governments, UNESCO and other education stakeholders to seize the opportunity of the 2020 disruption of life cycle for the maximum benefit of humanity. For this to happen we need exceptional leaders with extraordinary vision to transform education instead of ensuring children can keep learning and that every single child returns to school after the pandemic. Another challenge to be expected is the reduction in education budgets being under pressure as governments shift spending towards the health and economic response to the pandemic. The impact of schools closing on a generation of children will be immense on the long term. We must act now to save the education and life chances of generations of youth. At this time of unprecedented crisis, the world must come together to protect education and put it at the very heart of the global recovery effort. Recovery, not as before but as convenient and sustainable with the perspective requirements. It is time to expose youth to real life experiences; we need our children to learn about finance from characters like Jef Bezos or Bill Gates or Mukesh Ambani; to learn about psychology from John Anderson, Eliot Aronson and Ahmed Ukasha; to know approaches of math and physics as Elon Musk and Steve Wozniak. We shouldn't settle for less when it comes to building minds and souls of our children. With all due respect to teachers and university professors, they are not the only best option for qualifying and training our youth for tomorrow's challenges. However, those entrepreneurs are not teachers or willing to be, education specialists and strategists are
\end{abstract}




\section{Macrothink

required to set the vision and the procedures required to pave the way for highly practical competencies framework. Analgesics are no longer feasible.

Keywords: Education reform, Post pandemic strategy, Jef Bezos, Elon Musk, Bill Gates, Competencies framework 


\section{Introduction}

It is really ironic that the various fields of life are changing around us and technological transformation is invading every aspect of life while the public education system we currently know has been around for more than 150 years. We couldn't break free from the concept of classrooms staffed with 30 or 40 students being taught on a daily routine.

Even though the curricula have developed, the essence has stayed the same. Children are still taught in a standardized and industrialized way. As with anything that comes from centralized control, it is highly inefficient, bureaucratic, and wasteful. It is a fact that the general framework of educational system has changed in many regards, but the way students are taught has not. A teacher at the front and the children seated is the optimal way to learn for some students, but others struggle in this environment.

Children learn best in different ways. Some are best suited to learn through visual stimulation. Others may learn best through hands-on education (BLazar, 2017). The reality is that the current educational system doesn't really accommodate any learning style, nor does it aim for anything other than high test scores. It puts our children on a race track with a short sighted goal of securing highest grades as a final end. It is really tragic with alpha students reaching the highest scores in the high school phase feeling lost to decide which college to join, or which major to best fit their abilities. Then after a long journey of relentless efforts at school years they would never sacrifice their marks for admission in a less score college, even if they don't like the major. Pressure from culture, friends and parents is another weapon that forces them to enroll at colleges away from their capabilities and interests. I believe for a fact that the global workplace is losing hundreds and thousands of talents lost in their search of self-awareness. Governments are in a dire need to adopt designing a study path for school students that take several dimensions into consideration as future workplace requirements, competencies and skills.

\section{Discussion}

Children rarely are allowed to live as children. Play is stifled. Students used to get crammed into a classroom and taught in a standardized way. Creativity is restricted. They aren't allowed to harness their inquisitive minds. Questioning things is part of the analytic mind and a key to societal development, but this requires examinations. What is more daunting that we even exceeded this phase of basic needs to another level of future demands. In order for our children and youth to survive safely the overrunning of technology and automation transformation, we have a responsibility to reform the education system to a completely developed systems based on the full vocational and practical experiences from grade 1 . This requires a drastic change in curriculums, extra-curricular activities and the school pathways as well. I believe it's enough with improvements and modifications with the methods and media of learning! Decision makers have to take actions in this world in a way to build minds and souls of future generations. Enough with graduating mentally and spiritually limited capabilities! We have spent our lives learning how to answer questions of teachers, parents, university professors, managers ...etc. However, we should have been taught how to find answers and alternatives to activate the analytical mind. 
Universities aspire to develop students' thinking skills, but research shows that in practice, they tend to aim at facts and concepts in the disciplines, at the lowest cognitive levels, rather than the development of intellect. (Conley, 2007) Critical thinking is key to creating free and individual minds. It is also increasingly important especially after the COVID_19 pandemic, where the line between information and facts is so fine. In fact, a critical mind will question where data and information actually came from. Which resource did they come from? Is it actually reliable?

The issue we have today is that students are taught to test not to innovate and think. Whether the information makes sense or not, it doesn't matter as long as it is correct. This comes at a cost. Schools teach students what to think not how to think. There are important critical skills that aren't taught but acquired through brainstorming sessions and discussions. Do students truly question whatever they read or accept any claim blindly? Or, perhaps, do they accept it as long as it is being served by their trusted teachers? The current system is failing because it is offering the wrong type of education in relatively critical global circumstances. World governments must develop individual minds, not mindless repetitive shadows.

Regardless of the learning theories and development attempts of learning styles, it is evident that the classroom system is outdated and the whole situation has aggravated after the 2020 world pandemic to home schooling system without any prior readiness. Literacy rates have stagnated since 1971, while there has been no progress in math since 1990 (Balfanz, 2007). So what are the causes of this stagnation? So why is testing such a bad thing? It teaches children how to absorb information. Children "learn for a test"(Bryk, 1993). However, once the test is taken, is the information truly absorbed? How long does it stay present in the mind? According to the neurobiologists, the brain quickly disregards information that is no longer required. Forgetting is an evolutionary strategy to promote the survival of the species (Corno, 1983).

It is clear that the current system is generally based upon memory; who can memorize the most information to prepare for the test. Is this really arming kids with the tools they need for adulthood. The dire need that I believe in transforming education system would have a significant reduction in the testing of retrieving and memorizing information and focus more on how to think.

Furthermore, the testing culture is putting a strain on both teachers' and students' mental health. Test results are the one and only judge on the student's capabilities. Logically speaking, it is considered as unfair life sentence that the student himself could unconsciously believe that it reflects his overall potential and acts accordingly (Farrington, 2012). Only those figures who revolt against conforming with the educational systems and taking risks of dropping out have the opportunity to rediscover themselves and surf waves of knowledge. Isn't it crystal clear that we have a serious problem with the basic structure of educational system that requires immediate action? Passing exams rather than equipping children with life skills such as team working, collaboration, and creative thinking has become the only concern for students, teachers and parents as well. This culture has to change now.

Educational institutions who claim excellence and precedence in many countries strive to fill 
students' minds with knowledge, forgetting about the real skills to innovate, think and apply (Conley, 2008). What is the benefit of education that wouldn't refine and modify one's behavior and attitudes? Having a closer look around ourselves, with all these changes in the life pace in regards of technology and automation, the world doesn't care about what the candidate know, what the world really cares about is what you can do with what you know.

Over two years of research involving interviews with executives, college teachers, community leaders, and recent graduates, Wagner defined the skills needed for Americans to stay competitive in an increasingly globalized workforce. As lined out in his book, "The Global Achievement Gap," (Wagner, 2010) that set the core competencies that every student must master before the end of high school is:

Critical thinking and problem solving (the ability to ask the right questions), Collaboration across networks and leading by influence, agility and adaptability, Initiative and entrepreneurialism, accessing and analyzing information, Effective written and oral communication Curiosity and imagination.

For his latest book, "Creating Innovators: The Making of Young People Who Will Change the World," Wagner has extended his studies to address the problem of how we teach students these skills. He has come to the conclusion that America's economic problems are based in its education system. "We've created an economy based on people spending money they do not have to buy things they may not need, threatening the planet in the process," (Wagner, 2012) he says. "We have to transfer from a consumer-driven economy to an innovation-driven economy." This case is aggravating in the eastern world as well. We have always been raised up on a mindset of consuming not producing and innovating, regardless of our needs and requirements. In order to target this problem from its roots, we have to work on shifting the mindsets of younger generations.

Before attempting this journey of education reform, we have to realize that the culture of schooling as we all know is radically contradictory to the culture of learning that produces innovators. There are four ways in which America's education system is restricting innovation:

1). Individual achievement is the focus: Students spend a bulk of their time focusing on improving their GPAs — school is a competition among peers. "But innovation is a team sport," says Wagner. "It requires some solitude and reflection, but fundamentally problems are too complex to innovate or solve by oneself."

2). Specialization is celebrated and rewarded: High school curriculum is structured using a system that is 125 years old that became crystal clear incompatible with the new norm after the pandemic COVID_19. According to research of extrapolating the future, learning to be an innovator is about learning to cross disciplinary boundaries and exploring problems and their solutions from multiple perspectives.

3). Risk aversion is the norm: penalizing mistakes is a real danger. The whole challenge in schooling is to figure out what the teacher wants. And the teachers have to figure out what the superintendent wants or the state wants. It's a compliance-driven, risk-averse culture. 
Innovation, on the other hand, is grounded in taking risks and learning via trial and error.

4). Learning is profoundly passive: the school culture which we have to suffer from for long years to be paralyzing to our children's capabilities and potentials have diminished through the home schooling years of COVID-19 generating a more chaotic environment at home. The prospective educational system has to be tailored for pushing children grow up to find passion, not just academic achievement. Consequently, this passion will turn into a purpose. Such system could logically release persons with fingerprint in the world. The system should be innovation-driven.

Today's labor market requires job candidates with new set of abilities and competencies. Those competencies need to be tailored in the educational framework from the primary phase and could be divided into three main sectors; Technical and technological competences, character development competencies and foundational competencies. (Stein, 1996) Though names may seem common, but subjects and medium of delivery have to be updated and restructured including all the digital advances needed.

Today's job list which is high in demand is very different to yesterday's production line worker. Rather than developing people to perform the same task day after day, we now need individuals who can think independently, change direction and contribute the insights and ideas that will lead to a breakthrough product. It is also worth mentioning that most of today's youth will be working in jobs that don't even exist yet (Dawes, 2011). So as career opportunities emerge over time, those who are curious and adaptable are more likely to thrive than those who simply obtain technical skills. Basically, the days of relying purely on textbooks are long gone. Students, who in many cases will have become accustomed to technology at home, can now hone their digital skills and learn new ones when at school ranging from coding to online research to basic data analysis, all of which will stand them in good stead when they enter the world of work.

Although teachers, leaders and developers are key players in this new approach to education; governments, too, have a critical role to play. This is why in this paper I need to focus on the role of governments in leading a world project of restructuring the educational system. They could start by setting a vision of future requirements of skills and competencies, and then set a strategic plan of three basic dimensions of study fields. The plan should also encompass the teachers' development in order to empower them for the new educational system and its enablers of technology.

When it comes to funding, although education funding has traditionally been term-based, which limits students' ability to progress at an advanced pace, governments should consider more flexible funding mechanisms that support students as they progress from one phase to another based on demonstrated mastery, rather than rigid spring and fall terms (Planty, 2013). We have to admit that closing the $21^{\text {st }}$ century skills gap won't happen overnight. It requires a fundamental realignment of deeply rooted education systems, as well as a collaborated effort from teachers, technology developers, students and policymakers.

Practically speaking, The Covid-19 pandemic reveals the importance of using technology and 
communication apps in every aspect of life. Wishing the best for the next generation or wanting them to succeed is not enough. So this global project won't happen without tapping into the vast potential and power of digital technology. In many countries this is already happening and there's much more to be done. Furthermore, a more solid education system should be subject to global competition in which strong developed countries are racing with others who are economically less fortunate; on the contrary, it should be dealt with as a critical issue as global warming, a unification of efforts to save humanity.

The gap between what education systems provide and what our societies demand is likely to widen further. There is a risk that education becomes our next steel industry, and schools a relic of the past. But to transform schooling at scale, we need not just a radical, alternative vision of what is possible, but also smart strategies that help make change in education happen. Policy makers face tough choices when evaluating policy alternatives; they need to weigh the potential impact against the economic and political cost of change. Should they pursue what is most technically feasible? What is most politically and socially feasible? What can be implemented quickly? What can be sustainable over a sufficient time horizon?

We can rely on specialized entities that would help in giving us indications of what need to be done based on statistical figures about the performance of students in different schools. PISA is an international organization that evaluates educational systems by measuring 15 -year-old school pupils' scholastic performance on mathematics, science, and reading. It was first performed in 2000 and then repeated every three years (Coleman, 1987). Its aim is to provide comparable data with a view to enabling countries to improve their education policies and outcomes. It measures problem solving and cognition. So knowledge is only as valuable as our capacity to act on it. The reality is that many good ideas get stuck in the process of policy implementation.

When the Covid-19 pandemic strikes, governments came under pressure to sustain education services within a short period of time. I personally see this period as a disruptive force that urges ambitious reform agendas and develop strategic plans to achieve well modified education system. I guess the challenges are not limited to designing reforms, but also in how reforms can be put into practice successfully. So what is holding back change in education and why do great plans fall by the wayside? Many researchers have studied the implementation of education reform over many years, and have developed important insights into how plans are turned into practice. One reason for the difficulty in reforming education is simply the scale and reach of the sector. Generally schools, colleges, universities and other educational institutions are among the biggest recipients of public spending (Maehr, 1997). And because everyone has participated in education, everyone has an opinion about it. Everyone supports education reform, except when it might affect their own children. Even those who promote change and reform often revise their views when they are reminded what change actually entails.

The reason why it is so hard to move education systems forward is that there is a much larger, invisible part under the waterline. This invisible part is composed of the interests, beliefs, motivations and fears of the people who are involved. It seems like very few lacks the 
audacity to take full responsibility of taking bold decisions that may result in drastic changes ending up with superficial modifications of no added value. This is where unexpected collisions occur, because this part tends to evade the radar of public policy. Policy makers are rarely successful with education reform unless they help people recognize what needs to change (Adelman, 1997), and build a shared understanding and collective ownership for change. I believe that creating the right policy climate with accountability measures designed to encourage innovation and development, rather than compliance.

What may be challenging to the prospected world education reform as well is the vast conflict of interests among all the stakeholders. The potential loss of advantages or privileged positions is of particular importance in education reform, because the vast structure of established, usually public, providers means that there are extensive vested interests (Bruch, 2018). As a result, the status quo has many protectors, stakeholders in education who stand to lose a degree of power or influence if changes are made. Even small reforms can involve massive reallocations of resources, and touch the lives of millions. This makes it essential to have broad political support for any proposed reform. In essence, education reform will not happen unless educators implement and own it.

Education ministries have been at the frontline of some of the most visible public policy reforms on issues related to improving the quality and status of teachers, strengthening accountability, ensuring sufficient school places, and controlling and financing higher education (Firestone, 1998). Education policy makers know only too well the difficulty of securing stable financing for expanding tertiary education, whether by reallocating funding from other areas of public expenditure, or imposing tuition fees. Reforms that entail more testing of students often encounter resistance from teachers; reforms to vocational education might be resisted by parents who are skeptical about the promised benefits.

The question of who will benefit from reforms and to what extent has always been under discussion. This state of uncertainty is acute in education because of the range of people involved, including students, parents, teachers, employers and trade unions. Uncertainty about costs is problematic because education infrastructure is large and involves multiple levels of government, each often trying to minimise or shift the costs of reform. Assessing the relative costs and benefits of reform in education is also difficult because of the large number of intervening factors that can influence the nature, size and distribution of any improvements (Haynes, 1997). The investment may be expensive over the long term, while in the short term it is rarely possible to predict clear, identifiable results from new policies, especially given the time lags between implementation and effect.

Teachers are generally viewed positively by the public, even when there is great dissatisfaction with education systems. Teachers also tend to command greater public trust than politicians, so any resistance to reform on their part is likely to be effective. Even when parents have a poor opinion of the education system, they will generally view their children's school and its teachers positively (Turner, 1998). Implementing reforms is therefore often impossible without the co-operation of education staff. They can easily undermine reforms in the implementation phase, while blaming policy makers for having attempted misguided 
reforms in the first place. And teachers in many countries are well organized. But in fairness, many teachers have suffered from years of incoherent reforms that disrupt rather than improve education practice because they prioritize variable political interests over the needs of learners and educators. Many of these efforts to reform do not draw on the expertise and experience of teachers themselves. So teachers know that the easiest approach for them may be simply to wait out attempts at reform.

The toughest challenge to policy implementation of education reform goes back to the way in which we manage and govern educational institutions. Public education was invented in the industrial age, when the prevailing norms were standardization and compliance, and when it was both effective and efficient to educate students in batches and to train teachers once for their working lives (Gottfried, 2017). Due to the current challenges facing the world nowadays, the reformation would exceed training the teachers and restructuring the educational environment. It requires the engagement of big industrial companies as well as businessmen who lead huge projects in the private sector. They owe their country more than taxes such as knowledge transfer. Building future generations is a paramount necessity for sustainable world.

This structure, inherited from the industrial model of work, makes change a very slow process. Even the most agile countries revise their curriculum only every six to seven years. But the rapid pace of change in most other domains makes that response far too slow. Digital technologies that have revolutionized nearly every aspect of our lives have entered our children's classrooms surprisingly slowly (Kane, 2014). Even when there are attempts to use new technology, it often seems to be misaligned with the needs of the curriculum. In short, the changes in our societies have vastly outpaced the structural capacity of our current governance systems to respond. And when fast gets really fast, being slower to adapt makes education systems seem glacial and disconnected.

The opinion that suggests that "Top down governance through layers of administrative structures is no longer working" needs reconsideration, especially in the world's latest circumstances of the pandemic of Corona-19. The challenge is to build on the expertise of the hundreds of thousands of teachers and tens of thousands of school leaders and to enlist them in the design of superior policies and practices (Conley, 2014). Though teachers and school leaders have firsthand experiences of most of the educational hurdles that may incapacitate the students' performance, still their feedback and findings are considered some of the inputs to the reformation project. Governments are far eligible to lead the whole process for advantages of being entitled by law to take agile legislation or decrees that may contradict with the burucracy of current systems.

When we fail to engage them in designing change, they will rarely help implement it. What successful reform requires is mobilizing the knowledge and experience of teachers and school leaders, the people who can make the practical connections between the classroom and the changes taking place in the outside world. That is the fundamental challenge of policy implementation today (Manolistsis, 2013). There are strong countervailing forces pushing for a shake-up of the status quo. At an individual level, education plays an increasingly important 
role in determining individual well-being and prosperity; at a macro level, education is associated ever more strongly with higher levels of social inclusion, productivity and growth. The emergence of the knowledge society and the upward trend in skill requirements only increase the importance of education. The cost of underperformance and underinvestment in education is rising. Strategies to overcome resistance to education reforms are similar in certain respects to those adopted in other areas. Reform is more easily undertaken in "crisis" conditions, although the meaning of "crisis" might be somewhat different in education.

"Crisis" as the one we are living today under the Corona-19 Pandemic is considered a pressing situation to undertake the global project of restructuring the world educational systems with insightful visions of the future competencies in a systematic organized processes, based on the reports or indexes released from international sources of futurology in the various fields of life (Madaus, 1988). Having schools shut down all over the world gives governments enough chance to build together a common framework of the skills, knowledge and attitudes required for the coming phase of our human life. But such a move can also open up new opportunities, such as creating a broader array of courses for students, strengthening teacher collaboration and professional development, or simply freeing up resources for other investments in education.

World governments should collaborate together to tackle the potential problems which educational systems may encounter. For example in Germany, smaller populations of school-aged children forced some states to merge different types of secondary school, the vocational, the general and the basic (Sebastian, 2012). The important side-effect of these changes was a reduction in the degree of tracking and stratification in the German school system and, by implication, a weakening of the impact that social background has on learning outcomes.

Similarly, the prospect of fewer upper secondary school graduates forced the government of Finland, only a few years after it created a new polytechnic sector, to launch ambitious reforms to reduce the number of tertiary institutions and alter how they were governed and financed (Chetty, 2014). As in other sectors, co-ordinated reforms in different parts of education systems have proved to be mutually reinforcing. Sometimes real opportunities are disguised as insoluble problems. This was the case in Scotland when the government, intending to initiate sweeping reforms to the curriculum, testing and leadership, started with an overhaul of teacher education, induction and pay.

The success of reforms to the curriculum and testing were seen as dependent on prior reforms that would have an influence on who teaches and how they are educated. But because education systems involve multiple levels of government, implementation of "comprehensive reform" is often difficult to co-ordinate. Denmark faced this problem when it proved difficult to synchronise reforms to strengthen national testing with the pre- and in-service education of teachers employed by municipalities (Cutler, 2006). Local and regional entities often do not have sufficient capacity to implement national policies. Federal education systems, such as those in Australia, Austria, Belgium, Brazil, Canada, Germany, Switzerland, the United Kingdom and the United States, share a different dilemma. 


\section{Mll Macrothink}

Global Journal of Educational Studies

ISSN 2377-3936

2021, Vol. 7, No. 2

Though the federal government in the United States, for example, can require states to set quality standards as a condition for receiving federal money for education, it cannot determine what those standards are. In 2009, state school officials and governors in the United States agreed on the principle of establishing national, common standards in core subjects but in 2015, these standards were still insufficiently implemented to affect teachers' practice in the classroom at scale (Conley, 2014). Germany was more successful in implementing national standards even though it too has a federal government. The unsatisfactory results assessment created huge pressure on policy makers to establish more rigorous and coherent school standards across the states, and to advance from traditional content based curricula towards competency-based learning.

Constantly prodded by federal authorities and an increasingly demanding public, the states progressively agreed and implemented such standards. Why was the effort so much more successful in Germany than in the United States? First of all, Germany took time to engage a wide range of stakeholders in the development project, trial and implementation of the standards. Second, along with the standards, the states developed a range of resources to implement them in classrooms, including guidelines for instructional design, lesson plans and pedagogy (Finn, 1997). Capacity to implement the standards was developed at all levels of the education system. Unlike the United States, the German states also put a premium on the improvement, rather than the accountability, function of these standards.

I believe both national and international standards should be integrated with regard to the world demands of future jobs. Monitoring progress wouldn't be easy and will require commitment and diligence from all stakeholders. It requires co-ordinating policy development across levels of government; it is also hard to align the perspectives of different government departments. But if education is to be developed over a lifetime, then a broad range of policy fields need to be involved, including education, family, employment, industrial and economic development, migration and integration, social welfare and public finance (DeAngelis, 2011). A co-ordinated approach to education policies allows policy makers to identify policy trade-offs, such as between immigration and labor market integration, or between spending on early education or investing in welfare programs later on.

Creating linkages between different policy fields is also important to ensure efficiency and avoid duplication of effort. But a whole-of-government approach to education is not easy to achieve. Ministries of education will naturally focus on building strong education foundations for life, with due emphasis on transferring knowledge, skills and values (Goldhaber, 2000). Ministries of employment, by contrast, are mainly concerned with getting unemployed workers into work through short-term, job specific training. Ministries of the economy might be more interested in the skills needed to secure long-term competitiveness.

More generally, Policy makers need to build broad support about the aims of education reform and engage stakeholders, especially teachers, in formulating and implementing policy responses. External pressures can be used to build a compelling case for change. All political players and stakeholders need to develop realistic expectations about the pace and nature of reforms (Gamoran, 1987). Efforts to overcome resistance to reform will be wasted if 
education administrations do not have proper knowledge, professional know-how and adequate institutional arrangements for the new tasks and responsibilities included in the reforms. Successful reform might require significant investment in staff development, or clustering reforms to build capacity in related institutions.

This also means that reform needs to be backed by sustainable financing. The right governance in the right place. Education systems extend from local schools to national ministries. The responsibilities of institutions and different levels of government vary from country to country, as do the relative importance and independence of private providers. Reforms need to take into account the respective responsibilities of different players (Frederiksen, 1989). Some reforms may only be possible if responsibilities are well aligned or reallocated. Layers of regional government might be good at identifying local needs, but they might not be the right vantage point from which to monitor progress towards overall goals and objectives. As obtaining, managing and accessing information have become easier and cheaper, education systems can capitalize on collecting better and more relevant data to track individual and institutional performance, locally, nationally and internationally (Rivkin, 2005). There needs to be progression from initial reform initiatives towards building self-adjusting systems with feedback at all levels, incentives to react and tools to strengthen capacities to deliver better outcomes. Investment in change management skills is essential. Teachers need reassurance that they will be given the tools to change. Their motivation to improve their students' performance should be recognized too. "Whole-of-government" approaches can include education in more comprehensive reforms. It is worth looking at these aspects in greater detail.

The diversity of views on education reform makes policy making particularly challenging, especially given that policy makers often represent one of the stakeholder groups: government authorities. On the one hand, policy makers and parents tend to value quality assurance and accountability. They make the point that schools are public institutions, supported by taxpayers' money, and that the public has a legitimate interest in the quality of teaching (Steinberg, 1996). Summative teacher appraisal provides a way for school principals to reward excellence and commitment, and the public, their legislators, local boards of education and administrators with the means to monitor and ensure the quality of teaching. But teachers and their organizations often reject summative appraisals as tools for control; they favor more formative approaches.

By studying other cases where divergent views have been successfully reconciled we find that The Czech Republic, for example, began developing a standardized section of the school-leaving examination in 1997, but the section was only introduced 14 years later, in 2011. During the intervening time, several models were developed, pilot versions were implemented, and fundamental features were modified several times (MacNeil, 2009). The reforms were hotly debated, particularly among the country's political parties, which could not reach consensus on the approach to the examination. Setting the direction is another priority to clearly communicate a long-term vision of what is to be accomplished for student learning. Individuals and groups are more likely to accept changes that are not necessarily in their own interests if they and society at large understand the reasons for these changes and 
can see the role they should play within the broad strategy.

To achieve this, the evidence base of the underlying policy diagnosis, research findings on alternative policy options and their likely impact, and information on the costs of reform versus inaction should be disseminated widely in a language that is accessible to all. For instance, in order to convince teachers of the need to reform standardized student tests, it is critical that teachers understand and support the broader goals of the assessment, and the standards and frameworks underlying the assessment. Resistance to reform is often due to incomplete information about the nature of the proposed policy changes, their impact, or whether or not the stakeholders involved - including the general public - will be better or worse off. Opposition to change can also signal that the public has not been sufficiently briefed on or prepared for reform; it can also indicate a lack of social acceptance of policy innovations. This highlights the importance of making the underlying evidence available to convince educators and society at large. It involves raising awareness about how difficult decisions were made, enhancing the national debate and sharing evidence on the impact of different policy alternatives. That is the way to build a solid consensus.

Building a consensus is extensive evidence of the importance of consensus if policy reforms are going to be successful. At the same time, given the diversity of stakeholders in education, consensus might wind up meaning agreement at the level of the lowest common denominator; and that may be insufficient to lead to genuine improvement. Hence, strategic leadership is at the heart of successful education reform. Consensus can be fostered through consultations and feedback that allow concerns to be taken into account, and thus reduce the likelihood of strong opposition by some stakeholder groups. Regular involvement by stakeholders in policy design helps build capacity and shared ideas over time. Engaging stakeholders in the development of education policy can cultivate a sense of joint ownership about the need, relevance and nature of reforms.

We have to understand that teachers are key players in the world project of education reform which may include a reengineered strategy of evaluating teachers especially after the COVID-19 Pandemic. This evaluation strategy may face some resistance because of objections from the Teachers' Association about the composition of the evaluation system, and the fact that the system focused on punishment rather than improvement. Nevertheless, teacher evaluation continued to be a topic of public and political concern throughout the 1990s (Rockoff, 2004).

As a result of this participative approach, schools now show considerable support for and commitment to evaluation and assessment strategies. While there are, of course, differences of views, there seems to be an underlying consensus on the purposes of evaluation and an expectation among stakeholders to participate in shaping the national agenda. Policy making in some of the European countries as Norway is characterized by a high level of respect for local ownership (Campbell, 2008). This is evident in the development of the national evaluation and assessment framework. Schools have a high degree of autonomy regarding school policies, curriculum development, and evaluation and assessment. There is a shared understanding that democratic decision making and buy-in from those concerned by 
evaluation and assessment policy are essential for successful implementation. In addition, the government does a lot to build and strengthen capacity at local levels and to bring local communities together to compare notes.

In Finland, the objectives and priorities for educational evaluation are determined in the Evaluation Plan, which is crafted by the Ministry of Education and Culture in collaboration with the Education Evaluation Council, the Higher Education Evaluation Council, the National Board of Education and other key groups (Clotfelter, 2010). The members of the Education Evaluation Council represent the education administration, teachers, students, employers, employees and researchers. A monitoring commission in the French Community of Belgium was given a key role in monitoring the education system. It has two main missions: co-ordinate and review the coherence of the education system, and follow the implementation of pedagogical reforms. Its membership reflects all the relevant actors in the education system: school inspectors, school organizers, researchers, teachers' unions and parents' representatives.

The involvement of practitioners, teachers, other education staff and their unions, in producing, interpreting and translating research evidence into policy can give these practitioners a strong sense of ownership and strengthen their confidence in the reform process. Engaging teachers to help design reform the process of developing policy is more likely to yield consensus if there is a range of stakeholders involved from the outset. Regular interactions help build trust and raise awareness of the concerns of others, creating a climate of compromise. When favors of stakeholders contrast mistrust arises, and when clinging to positions becomes more important than using common sense, we lose the capacity to change and develop ideas based on dialogue. Another dimension needs to be taken into consideration is that where teachers are not genuinely involved in the design of reforms, they are unlikely to help with their implementation. This needs to be more than lip-service.

In fact, the majority of teachers in both the eastern and western world need qualification framework that is beyond training programs. But the bigger problem is that policy makers often do not have much of a sense of the capacity and expertise that is dormant among their teachers, because all their efforts focus on getting government prescription into classrooms, rather than getting the good practice from great classrooms into the education system (Finn, 1997). The point is that teachers will accept evaluation more easily if they are consulted as the process is being designed. In addition, this is a good way to recognize and capitalize on their professionalism, the importance of their skills and experience, and the extent of their responsibilities. If teacher-appraisal procedures are designed and implemented only from "above", there will be a "loose coupling" between administrators and teachers. It could mean teachers are less engaged and less willing to identify any potential risks in the procedures.

Engaging teachers and school leaders in their own appraisal, such as by setting objectives, self-appraisal and preparing individual portfolios, can create a stronger sense of empowerment among teachers and school leaders and, therefore, ensure that the process is successfully implemented. Education authorities have a lot to gain from listening to the advice of experienced teachers. These teachers can identify good teaching practices and the 
best ways to evaluate their peers. An evaluation system is more likely to be successful if it is accepted by professionals and is perceived as useful, objective and fair. The need to engage the teaching profession extends beyond politics and pragmatism. One of the main challenges for policy makers in an increasingly knowledge-based society is how to maintain teacher quality and ensure that all teachers continue to engage in professional learning.

Research on the characteristics of effective professional development indicates that teachers need to be involved in analyzing their own practice in light of professional standards, and in analyzing their students' progress in light of standards for student learning. Introducing pilot projects and continuous evaluation Experimenting with policy and using pilot projects can help build consensus, allay fears and overcome resistance by evaluating proposed reforms before they are fully introduced (Hanushek, 2010). It is equally important to review and evaluate reform processes periodically after full implementation. Teachers and school leaders are more likely to accept a policy initiative if they know that they will be able to express their concerns and provide advice on making adjustments.

In New Zealand, the Ministry of Education commissions independent evaluations to monitor national policies. For example, the implementation of the curriculum in English medium schools was monitored by the Education Review Office. National standards were monitored by the ministry and the Education Review Office, using samples of schools, in a project run by a contracted evaluation team. The information obtained from these reviews was complemented by survey data, information from reports of the Education Review Office, and results from national and international assessments (Planty, 2010). In a range of countries, external evaluators typically collect feedback from schools and other stakeholders on their experience with the evaluation process in order to monitor the implementation of that process.

One of the biggest obstacles to reform is inadequate capacity and resourcing, often because the resource implications are underestimated in scope, nature and timing. The main shortcoming is often not a lack of financial resources, but a dearth of human capacity at every level of the system. The Alberta Initiative for School Improvement, in Alberta, Canada, was created in 1999 to address exactly this kind of problem. It encourages teachers, parents and the community to work together to introduce innovative projects to meet local needs (Guryan, 2008). The initiative's platform allows schools and school districts to improve teachers' professional capacity in curriculum and pedagogic development through a process of collaborative inquiry. The initiative was the result of the close partnership between the Alberta Teachers' Association, the Alberta government and other professional partners, such as the Alberta School Boards Association. The Alberta Teachers' Association spends around half of its budget on professional development, education research and public advocacy to build a stronger and more innovative teaching profession. Teaching and Learning International Survey (TALIS) of 2013 clearly shows Alberta's strong commitment to teacher professionalism. Alberta's teachers were more likely to report participating in professional learning than teachers in other countries and economies. Only 4\% of Alberta's teachers reported that they had never participated in professional learning activities compared with other countries. Teachers need to have time not only to reflect on their own practices, but to 
avail themselves of professional development activities when they are offered. Teacher education for reform is also often needed to ensure that all stakeholders are equipped and prepared to assume the new roles and responsibilities that are required of them. Timing is everything.

A week is a long time for a political leader, but successful education reform often takes years. First of all, as I mentioned before, there is often a substantial gap between the time at which the initial cost of reform is incurred, and the time when the intended benefits of reforms materialize. Why underinvestment in early childhood education and care is so persistent, despite the extensive evidence that these investments have particularly large social returns and a significant influence on what happens in subsequent schooling needs to be reconsidered (Guryan, 2008). In Germany, parents must pay a fee for enrolling their child in pre-school programs, but it has proved impossible to impose even the most modest fees on Germany's university students, where there would be much stronger justification for doing so. The reason is not just that children have no lobby behind them, it is also because it takes such a long time for the fruits of improvements in early childhood education to become apparent.

That is also why we tend to try to find a way to afford the most expensive medical treatment when foregoing it would immediately compromise our health, while we are all too often ready to accept serious shortcomings in education services when their consequences won't be apparent for years. In addition, reform measures are often best introduced in a specific sequence. For example, one element - curriculum reform - may require prior reform in pre-service and in-service teacher education in order to be effective. It is also crucial that there is, from the outset, a clear understanding of the timing of intended, implemented and achieved reforms. Time is also needed to learn about and understand the reform measures, build trust, and develop the necessary capacity to move on to the next stage of policy development.

However, while most studies reported that governments had established arrangements for consultation, half of the respondents felt only partially engaged in these consultation structures. Moreover, unions considered themselves generally more engaged in policy development than in implementation. This suggests that the mere existence of formal structures alone does not guarantee actual engagement. Perspectives sometimes varied between unions in the same country, reflecting the fact that governments may have different relations with unions representing different sectors of the workforce.

Union representatives were also asked to identify those areas of education policy that were under discussion. Almost all respondents mentioned teachers' professional development, followed by working conditions and equity issues. Issues concerning the curriculum, pay, support for students with special needs, teacher evaluation, student assessment and institutional evaluation were also mentioned by a majority of unions. One in three reported that there are productive discussions on student behaviour. Issues rarely mentioned were education research, school development and teaching councils. Similar questions were asked about training policies.

There are opponents of teachers' unions who see the unions as interfering with promising 
school-reform programmes by giving higher priority to their own bread-and-butter issues than to what the evidence suggests students need to succeed. But many of the countries with the strongest student performance also have strong teachers' unions (Madaus, 1988). There seems to be no relationship between the presence of unions in a country, including and especially teachers' unions, and student performance. But there may be a relationship between the degree to which teachers' work has been professionalised and student performance. Indeed, the higher a country ranks on the PISA league tables, the more likely it is that the country works constructively with its teachers' organisations and treats its teachers as trusted professional partners. In Ontario, Canada, the government signed a four-year collective bargaining agreement with the four major teachers' unions in 2014.

In reaching the accord, the ministry was able to negotiate items that were consistent with both its education strategy and the unions' interests, thus providing a basis for pushing forward the education agenda while creating a sustained period of labor peace that allowed for a continuous focus on improving education. I have observed that the nature of the relationship between governments and teachers' unions often reflects the work organization in education. In a highly industrialized work organization, where teachers are expected to do the same work that their counterparts decades ago did, and for similar pay, this environment consequently encourages unions to focus on pay and working conditions. That, in turn, tends to lead to stakeholder relationships that are top-down and antagonistic.

By contrast, a highly professional work organisation, where the government enables and offers incentives to teachers, and where the teaching profession is characterised by diverse careers, ownership and innovative ways of working, is conducive to developing a strategic, principled and professional working relationship between the government and unions. In that sense, implementing change on the ground would always hinge on engaging teachers' organizations. The idea was to bring together ministers and unions from around the world to address issues that are difficult to tackle nationally, often because of entrenched stakeholder interests (Madus, 1988). We felt that it was time for governments, teachers' unions and professional bodies to redefine the role of teachers, and to create the support and collaborative work organization that can help teachers grow in their careers and meet the needs of 21 st-century students.

Since then, we have invited ministers and teachers' union leaders from the best-performing and most rapidly improving education systems each year in a unique global effort to raise the status of the teaching profession. Of course, both ministers and union leaders had had many international meetings before, but what makes the International Summit on the Teaching Profession unique is that they are sitting next to each other. They can listen to ministers and union leaders from other countries who might have successfully broken the stalemates in which they are stuck in their own country.

\section{Conclusion}

It's worth mentioning that the compliance-driven and risk-averse educational culture is really depriving states from generating more innovators and problem-based mindsets that would be of great support to the development journey. Long before the CORONA pandemic, the 
educational system has been suffering from aged methodologies that have been proving every single day to be obsolete and incompatible with the modern world needs. This paper could be considered as a call to world governments to immediately initiate a comprehensive strategic plan of education to move from the consumer-driven economy to the innovation- driven economy. This could only be manifested through a generation aware of the current and future challenges. Furthermore, curiosity and multidisciplinary specializations are our way out to surviving a sustainable work. Those who are curious and adaptable are more likely to thrive than those who simply obtain technical skills. It won't be feasible any longer to be satisfied with the one or double majors which are provided by our academic institutions. This is a serious call to commence "world Governments' Project of Education Reform" which relies on three main pillars: multidisciplinary majors, vocational skills and business celebrity mentors and coaches.

Enriching education curriculums with real experiences of global successful figures in the various fields of life would be a serious approach towards rea change. Their life struggles and success journey need to be impeded as modules of study. Their vision of economy and investments should be chapters of students in various scholastic levels. The pursuit of just making sure they pay their full taxes is short-sighted and incapacitating than a greater hidden benefit. They owe a more significant responsibility to the world beyond paying taxes. Governments should focus on passing the life experiences of those successful figures to younger generations in educational systematic doses. I don't mean here the on and off interviews and TV shows they are invited to from time to time talking scatterly on their latest achievements. What I mean is turning their life journeys with the help of curriculum experts into scholastic and academic methodologies being taught under the supervision of ministries of education. Till now I couldn't get why a financially struggling university professor teach accounting and finance while ignoring the well-established empire build by figures as Elon Musk, Mukesh Ambani, Jef Bezos, Steve Jobs, Jack Ma and many others. This is not an underestimation of university professors' efforts as I myself belong to those people. But what I am suggesting here is that we can maximize the benefits of education if we engage those successful figures in restructuring a more vocational practical education system that would serve the high demands of the current and the future generations amongst this accelerating shifts in economy, technology and other fields.

I hopefully aspire this paper would resonate with governments vision that may be translated into a mega project of educational system reform. Decision makers need to conceptualize the importance of taking an immediate action as necessary as any global critical health emergency. Steering committees should target areas of training where students, teachers, community and decision makers drive productive discussions about identification of the curriculum, framework of the professional development, equity issues, pay, adult learning and working conditions. Spotting factors where there is room for improvement, especially when it comes to establishing union-government dialogue across the board would be a pivotal target. Governments need to play a more active role in encouraging a dialogue with relevant unions by recognizing and supporting such mega project. This is not easy to do, because there are many thorny issues that separate teachers and policy makers. To conclude, I hope that my 
call would reach any of those far-sighted decision-makers that would consider my proposal as the kick start of a real treatment of the world education system. Furthermore, I encourage researchers to delve deep into what I presented here for the benefit of our future generations.

\section{References}

Adelman, H. S., \& Taylor, L. (1997). Addressing barriers to learning: Beyond school-linked services and full-service schools. American Journal of Orthopsychiatry, 67(3), 408-421.

$\mathrm{Au}$, W. (2007). High-stakes testing and curricular control: A qualitative metasynthesis. Educational Researcher, 36(5), 258-267.

Aucejo, E., \& Romano, T. F. (2016). Assessing the effect of school days and absences on test score performance. Economics of Education Review, 55, 70-87. https://doi.org/10.1016/j.econedurev.2016.08.007

Balfanz, R., Herzog, L., \& MacIver, D. J. (2007). Preventing student disengagement and keeping students on the graduation path in urban middle-grades schools: Early identification and effective interventions. Educational Psychologist, 42(4), 223-235.

Bill and Melinda Gates Foundation. (2010). Learning about Teaching: Initial Findings from the Measures of Effective Teaching Project. Seattle: Author.

Blazar, D., \& Kraft, M. (2017). Teacher and teaching effects on students' behavior and attitudes. Educational Evaluation and Policy Analysis, 39(1), 146-170.

Bruch, S. K., \& Soss, J. (2018). Schooling as a formative political experience: Authority relations and the education of citizens. Perspectives on Politics, 16(01), 36-57. https://doi.org/10.1017/S1537592717002195

Bryk, A. S., \& Hermanson, K. L. (1993). Chapter 10: Educational indicator systems: Observations on their structure, interpretation, and use. Review of Research in Education, $19(1), 451-484$.

Campbell, D. E. (2008). Voice in the classroom: How an open classroom climate fosters political engagement among adolescents. Political Behavior, 30(4), 437-454.

Chetty, R., Friedman, J. N., \& Rockoff, J. E. (2014). Measuring the impacts of teachers II: Teacher value-added and student outcomes in adulthood. American Economic Review, 104(9), 2633-2679.

Clotfelter, C. T., Ladd, H. F., \& Vigdor, J. L. (2010). Teacher credentials and student achievement in high school: A cross-subject analysis with student fixed effects. Journal of Human Resources, 45(3), 655-681.

Coleman, J. S., \& Hoffer, T. (1987). Public and Private High Schools: The Impact of Communities. New York, NY: Basic Books.

Conley, D. T. (2007). Redefining College Readiness. Eugene, OR: Educational Policy Improvement Center. 


\section{$\Lambda$ Macrothink}

Global Journal of Educational Studies ISSN 2377-3936

Conley, D. T. (2008). Rethinking college readiness. New Directions in Higher Education, 2008(144), 3-13.

Conley, D. T., \& French, E. M. (2014). Ownership of learning and self-efficacy as key components of college readiness. American Behavioral Scientist, 58(8), 1018-1034.

Conley, D. T., Beach, P., Thier, M., Lench, S. C., \& Chadwick, K. L. (2014). Measures for a College and Career Indicator: Final Report. Eugene, OR: Educational Policy Improvement Center.

Corno, L., \& Mandinach, E. B. (1983). The role of cognitive engagement in classroom learning and motivation. Educational Psychologist, 18(2), 88-108.

Cutler, D. M., \& Lleras-Muney, A. (2006). Education and Health: Evaluating Theories and Evidence. NBER Working Papers 12352. Cambridge, MA: National Bureau of Economic Research.

Dawes, N. P., \& Larson, R. (2011). How youth get engaged: Grounded-theory research on motivational development in organized youth programs. Developmental Psychology, 47, 259-269. http://dx.doi.org/10.1037/a0020729

DeAngelis, K. J., \& Presley, J. B. (2011). Teacher qualifications and school climate: Examining their interrelationship for school improvement. Leadership and Policy in Schools, 10(1), 84-120.

Farrington, C. A., Roderick, M., Allensworth, E., Nagaoka, J., Keyes, T. S., Johnson, D., \& Beechum, N. O. (2012). Teaching Adolescents to Become Learners: The Role of Noncognitive Factors in Shaping School Performance. Chicago, IL: University of Chicago Consortium on Chicago School Research.

Finn, J. D., \& Rock, D. A. (1997). Academic success among students at risk for school failure. Journal of Applied Psychology, 82(2), 221-234.

Firestone, W. A., Mayrowetz, D., \& Fairman, J. (1998). Performance-based assessment and instructional change: The effects of testing in Maine and Maryland. Educational Evaluation and Policy Analysis, 20(2), 95-113.

Frederiksen, J. R., \& Collins, A. (1989). A systems approach to educational testing. Educational Researcher, 18(9), 27-32.

Gamoran, A. (1987). The stratification of high school learning opportunities. Sociology of Education, 60(3), 135-155.

Goldhaber, D. D., \& Brewer, D. J. (2000). Does teacher certification matter? High school teacher certification status and student achievement. Educational Evaluation and Policy Analysis, 22(2), 129-145.

Gottfried, M. A. (2017). Linking getting to school with going to school. Educational Evaluation and Policy Analysis, 39(4), 571-592. 


\section{MInstitute Macrothink $_{\text {Int }}$}

Global Journal of Educational Studies

ISSN 2377-3936

2021, Vol. 7, No. 2

Guryan, J., Hurst, E., \& Kearney, M. (2008). Parental education and parental time with children. Journal of Economic Perspectives, 22(3), 23-46.

Hanushek, E. A., \& Rivkin, S. G. (2010). Generalizations about using value-added measures of teacher quality. American Economic Review, 100(2), 267-271.

Haynes, N. M., Emmons, C., \& Ben-Avie, M. (1997). School climate as a factor in student adjustment and achievement. Journal of Educational and Psychological Consultation, 8(3), 321-329.

Kane, T., Kerr, K., \& Pianta, R. (2014). Designing Teacher Evaluation Systems: New Guidance from the Measures of Effective Teaching Project (1st ed.). San Francisco, CA: Josey Bass.

MacNeil, A. J., Prater, D. L., \& Busch, S. (2009). The effects of school culture and climate on school achievement. International Journal of Leadership in Education, 12(1), 73-84.

Madaus, G. F. (1988). The influence of testing on the curriculum. In L. Tanner (Ed.), Critical Issues in Curriculum, NSSE Yearbook, Part 1 (pp. 83-121). Chicago, IL: University of Chicago Press.

Maehr, M. L., \& Meyer, H. A. (1997). Understanding motivation and schooling: Where we've been, where we are, and where we need to go. Educational Psychology Review, 9(4), 371-409.

Manolitsis, G., Georgiou, G. K., \& Tziraki, N. (2013). Examining the effects of home literacy and numeracy environment on early reading and math acquisition. Early Childhood Research Quarterly, 28(4), 692-703.

Planty, M., \& Carlson, D. (2010). Understanding Education Indicators: A Practical Primer for Research and Policy. New York, NY: Teachers College Press.

Rivkin, S. G., Hanushek, E. A., \& Kain, J. F. (2005). Teachers, schools, and academic achievement. Econometrica, 73(2), 417-458.

Rockoff, J. E. (2004). The impact of individual teachers on student achievement: Evidence from panel data. The American Economic Review, 94(2), 247-252.

Sebastian, J., \& Allensworth, E. (2012). The influence of principal leadership on classroom instruction and student learning: A study of mediated pathways to learning. Educational Administration Quarterly, 48(4), 626-663.

Stein, M. K., \& Lane, S. (1996). Instructional tasks and the development of student capacity to think and reason: An analysis of the relationship between teaching and learning in a reform mathematics project. Educational Research and Evaluation, 2(1), 50-80.

Steinberg, L. D., Brown, B. B., \& Dornbusch, S. M. (1996). Beyond the Classroom: Why School Reform Has Failed and What Parents Need to Do. New York, NY: Simon \& Schuster.

Turner, J. C., Thorpe, P. K., \& Meyer, D. K. (1998). Students' reports of motivation and 


\section{Macrothink}

Global Journal of Educational Studies

ISSN 2377-3936 2021, Vol. 7, No. 2

negative affect: A theoretical and empirical analysis. Journal of Educational Psychology, 90, 758-771.

Wagner, T. (2010). The Global Achievement Gap: Why Even Our Best Schools Don't Teach the New Survival Skills Our Children Need-And What We Can Do About It Paperback.

Wagner, T. (2012). Creating Innovators: The Making of Young People Who Will Change the World.

\section{Copyright Disclaimer}

Copyright for this article is retained by the author(s), with first publication rights granted to the journal.

This is an open-access article distributed under the terms and conditions of the Creative Commons Attribution license (http://creativecommons.org/licenses/by/3.0/). 